\title{
Lipid and Biosurfactant Based Core-Shell Type Nanocapsules having High Drug Loading of Paclitaxel for Improved Breast Cancer Therapy
}

Sameer S. Katiyar, Rohan Ghadi, Varun Kushwah, Chander Parkash Dora, Sanyog Jain*

Centre for Pharmaceutical Nanotechnology, Department of Pharmaceutics, National Institute of Pharmaceutical Education and Research, S.A.S Nagar, Mohali, Punjab-160062, India.

\footnotetext{
*To whom correspondence should be addressed: E-mail: sanyogjain@niper.ac.in, sanyogjain@rediffmail.com, Tel.: +91-172-2292055, Fax: +91-172-2214692
} 


\section{Methods}

\subsection{Characterization of nanoparticles}

Particle size, Polydispersity Index (PDI) and zeta potential of the nanoparticles were determined by dynamic light scattering (Nano ZS, Malvern Instruments, UK). PDI, which is a dimensionless number, was used as an indicative of particle size distribution in the sample of the nanoparticles.

\subsection{Determination of \% drug loading}

Drug loading was determined by direct method. Briefly, centrifugation was carried out at 5,000 rpm for 5 min to settle free drug. The supernatant was then subjected to centrifugation at 45,000 rpm for 40 min to settle the nanoparticles. Obtained pellet was then dissolved in ethanol to dissolve the lipids and extract drug. Presence of drug was quantified by validated HPLC method (Shimadzu CBM 20A model on C-18 column LiChrospher ${ }^{\circledR} 100$ (Agilent Technologies), dimension 4.6x250 $\mathrm{mm}$, with mobile phase Acetonitrile:Water $(55: 45 \mathrm{v} / \mathrm{v})$ in isocratic mode at a flow rate of $1 \mathrm{ml} / \mathrm{min}$, $227 \mathrm{~nm}$ as analytical wavelength and $20 \mathrm{ml}$ injection volume). Mobile phase was utilized for dilution wherever required. Percentage entrapment efficiency $(\% \mathrm{EE})$ was calculated using the formula,

$$
\% \text { drug loading }=\frac{\text { Total amount of drug taken }- \text { Total unentrapped drug }}{\text { Total amount of drug taken }} * 100
$$

\subsection{Microscopic characterization of nanoparticles}

Scanning Electron Microscopy (SEM) and Transmission Electron Microscopy (TEM) were employed as microscopic characterization technique to characterize shape and morphology of nanocapsules. SEM (Hitachi S-3400N, Hitachi High-Tech Co., Japan) was utilized to examine surface morphology of the nanocapsules. In brief, nanocapsules were placed on an aluminum stub by adhesive carbon tape and sputter-coated (E-1010, Hitachi High-Tech Co., Japan) with gold- 
palladium alloy to make the surface conductive. The samples were examined at $10 \mathrm{kV}$. Similarly, TEM (FEI 187 Tecnai G2F20, Netherlands) was employed for the study of the nanocapsules morphology. The nanocapsules were diluted with ultra-pure grade water and placed on the carboncoated copper grid with phosphotungstic acid $(2 \% \mathrm{w} / \mathrm{v})$. The grid was air dried and sample was scanned at different magnifications with the transmission electron microscope

\subsection{Lyophilization}

Different lyoprotectants like mannitol, dextrose, sucrose, inulin and trehalose were screened based on particle size, PDI, \% drug loading in comparison of formulation before freeze drying. Physical parameters such as reconstitution time and appearance of cake were also evaluated for the freezedried formulation. Mannitol, dextrose, sucrose, inulin and trehalose were screened as lyoprotectants at $5 \% \mathrm{w} / \mathrm{v}$ concentration. Mannitol was screened out as the most favourable lyoprotectant in the case of developed formulation and was further evaluated at four different level of concentration $(2.5 \%, 5 \%, 7.5 \%, 10 \% \mathrm{w} / \mathrm{v})$.

\subsection{Powder X-Ray Diffraction (P-XRD)}

X-ray diffraction of PTX, MNT and lyophilzed product were recorded using Powder X-ray diffractometer (D8 advanced diffractometer, Bruker AXS GmbH, Germany) equipped with EVA software. Calibration alignment was done utilizing alumina powder. Standard Bragg-Brentano geometry was used to analyse phase distribution of powdered samples. Voltage supply of $40 \mathrm{kV}$ was applied to X-ray tube for maintaining current a t $40 \mathrm{~mA}$. Cu-k $\alpha$ (1.5406 $\AA$ wavelength) was used as radiation source. The samples were scanned from 40 to $4002 \theta$ with scan rate of 0.10 $2 \theta / \mathrm{min}$ at room temperature. 


\subsection{In vitro release study}

Briefly, free PTX and PTX loaded core-shell nanocapsules (equivalent to $1 \mathrm{mg}$ PTX) dispersed in release media were taken in dialysis bag (Molecular weight cut-off -14 KD, Sigma Aldrich). The release medium employed was phosphate buffer $\mathrm{pH} 7.4$ with $0.1 \%$ Tween ${ }^{\circledR} 80$ to maintain sink conditions. The dialysis bags were dipped in $20 \mathrm{~mL}$ of the release medium in centrifuge tubes. The release study was performed in shaker water bath at $37^{\circ} \mathrm{C}$ at 50 strokes $/ \mathrm{min}$ for $24 \mathrm{~h}$. At predetermined time points $1 \mathrm{~mL}$ of sample was withdrawn and replaced with same quantity of release medium. The samples were analyzed by HPLC method and \% cumulative drug release was determined. After the release profile was ascertained, different release kinetics were applied in two phases, namely, burst release phase and sustained release phase to evaluate the release mechanism.

\subsection{In vitro hemolytic toxicity}

The heparinized blood from Sprague Dawley rats was collected in microcentrifuge tubes. The blood was subjected to centrifugation $(3000 \mathrm{rpm})$ for $5 \mathrm{~min}$ at $4^{\circ} \mathrm{C}$ to separate red blood cells (RBCs) from plasma. The RBCs were washed thrice with isotonic PBS ( $\mathrm{pH} 7.4)$ to remove traces of plasma proteins. The RBCs collected were redispersed with isotonic PBS to prepare $1 \%$ RBCs suspension. A $900 \mu \mathrm{L}$ of this suspension was mixed with $100 \mu \mathrm{L}$ of different dendrimer formulations. The RBCs suspension mixed with PBS and Triton ${ }^{\mathrm{TM}} \mathrm{X}-100$ were used as negative and positive control, respectively. The samples were then allowed to incubate at $37^{\circ} \mathrm{C}$ for $1 \mathrm{~h}$ and further centrifuged at $3000 \mathrm{rpm}$ for $10 \mathrm{~min}$. The supernatant after its separation was allowed to stand at room temperature for $30 \mathrm{~min}$ in order to convert hemoglobin into its oxidized hemoglobin. The absorbance of oxygenated hemoglobin $(\mathrm{Oxy}-\mathrm{Hb})$ was measured spectrophotometrically at 540 $\mathrm{nm}$, and percentage hemolysis was calculated by using following equation:

$$
\% \text { Hemolysis }=\left(\mathrm{Ab}_{\mathrm{sam}} / \mathrm{AB}_{100}\right) * 100
$$


Where $\mathrm{AB}_{\text {sam }}$ is the absorbance of the sample and $\mathrm{AB}_{100}$ is the absorbance of the positive control.

The obtained RBCs were then visualized under SEM to study the morphological changes in RBCs.

\subsection{Qualitative and Quantitative cell uptake study}

After the cell confluency reached $90 \%$, culture media was removed followed by washing of cells 3-4 times with Hank's buffered salt solution (HBSS). The coumarin-6 (C-6) loaded nanocapsules were made by similar method as described in section 2.3 except using C- 6 dye instead of PTX. Thereafter, the cells were incubated for $3 \mathrm{~h}$ with C-6 loaded nanocapsules. After incubation, the media was aspirated and the cells were washed thrice to remove the extracellular particles. Finally, using 3\% paraformaldehyde (Merck, India) the cells were fixed and nuclei were stained with DAPI $(10 \mu \mathrm{g} / \mathrm{mL})$. Finally, the cells were observed under CLSM. In a separate set of experiments conducted for quantitative cell uptake studies, MCF-7 cells were incubated with PTX and PTX nanocapsules for different time intervals. After the incubation time was over, the cells were washed with HBSS three times to remove the extracellular drug. Further, using $0.2 \% \operatorname{Triton}^{\mathrm{TM}} \mathrm{X}-100$ the cells were permeabilized to extract the internalized drug with methanol. The cell lysate was collected and centrifuged (Sigma K300, USA) at $10000 \mathrm{rpm}$ for $10 \mathrm{~min}$ at $4^{\circ} \mathrm{C}$ and the supernatant was subjected to HPLC analysis for quantification of internalized drugs.

\subsection{Cell cytotoxicity assay}

After the MCF-7 cells were attached, free PTX and PTX nanocapsules containing fresh medium, were subjected to cells. The final concentration exposed to the cells was $0.01,0.1,1$, and $10 \mu \mathrm{g} / \mathrm{mL}$ (equivalent to free PTX) and incubated for 24, 48 and $72 \mathrm{~h}$. After the end of incubation, cells were subjected to washing with PBS pH 7.4. Later, $150 \mu \mathrm{L}$ of MTT (500 $\mu \mathrm{g} / \mathrm{mL}$ in PBS) was added into

each well followed by incubation for 3-4 $\mathrm{h}$ to facilitate formation of formazan crystals. MTT and formazan crystals were dissolved in $200 \mu \mathrm{L}$ of DMSO and plate was subjected to UV absorbance 
at $550 \mathrm{~nm}$ using ELISA plate reader (Biotek, USA). PTX concentrations required to inhibit growth by $50 \%\left(\mathrm{IC}_{50}\right)$ were ascertained from concentration dependent cell viability curves

$$
\text { Cell viability }(\%)=(\text { Abss/Absctrl }) 100
$$

Where Abss is the absorbance of the cells tested with various formulations and Absctrl is the absorbance of the control cells.

\subsection{Apoptosis assay}

The standard phosphatidyl serine externalization assay was performed to estimate the extent of apoptosis. Briefly, it was measured as a function of double label staining (Annexin V Cy3.18 conjugate; AnnCy3) and 6-carboxyfluorescein diacetate (6-CFDA). The cells stained with only green fluorescence were considered as live; those stained with both red and green were regarded as apoptotic, while cells stained only with red were considered as necrotic. Apoptosis index, ratio of the fluorescence intensity from the red fluorescence (originated from the Annexin V Cy3.18 conjugate, measure of apoptosis) normalized to that of green fluorescence (originated from the 6CFDA, measure of viable cells) was also calculated for the developed formulations.

\subsection{In vivo Pharmacokinetics}

The animals were randomly distributed into three groups Intaxel ${ }^{\circledR}$, Nanoxel ${ }^{\circledR}$ and PTX nanocapsules each containing 5 animals $(\mathrm{n}=5)$. All the formulations were administered via intravenous injection at a PTX dose of $5 \mathrm{mg} / \mathrm{kg}$ of body weight. The blood samples were collected from the tail vein into the heparinized micro-centrifuge tubes. Plasma was separated by centrifuging the blood samples at $10000 \mathrm{rpm}$ for $10 \mathrm{~min}$ at $4^{\circ} \mathrm{C}$. To $100 \mu \mathrm{L}$ of plasma, $200 \mu \mathrm{L}$ of acetonitrile was added to precipitate the plasma proteins and $25 \mu \mathrm{L}$ of internal standard docetaxel 
was also added. The samples were vortexed and centrifuged at 10,000 rpm for $10 \mathrm{~min}$. The supernatant was separated and analyzed for drug content by HPLC.

\subsection{In vivo anti-tumor efficacy}

Briefly, DMBA was administered orally in soybean oil to the rats at $45 \mathrm{mg} / \mathrm{kg}$ dose at weekly interval for three consecutive weeks. After 10 weeks of the last dose of DMBA, tumor bearing animals were separated and divided randomly into different treatment groups each containing 5 animals $(\mathrm{n}=5)$. Briefly, the treatment schedule involved administering $5 \mathrm{mg} / \mathrm{kg}$ of PTX intravenously (Intaxel ${ }^{\circledR}$, Nanoxel $^{\circledR}$ and PTX nanocapsules) every 5 days (total three doses). The last group, kept as control, received normal saline in a similar manner. The tumor volume was measured on every alternate day by measuring the tumor width (w) and length (l) with an electronic digital caliper by using the following formula; $(\mathrm{V})=1 * \mathrm{w}^{2} / 2$ up to 15 days.

\subsection{Organ toxicity study}

Briefly, animals were divided into four groups containing 6 mice each. Intravenous dose of Intaxel $^{\circledR}$, Nanoxel ${ }^{\circledR}$ and PTX nanocapsules $(5 \mathrm{mg} / \mathrm{kg}$ equivalent of PTX) were administered into mice and negative control (vehicle control) was kept to depict basal integrity of animals. On 8th day of the dosing, all the mice were humanely sacrificed and their blood was collected in microcentrifuge tubes, which were then centrifuged at $2500 \mathrm{rpm}$ for $5 \mathrm{~min}$ at $4^{\circ} \mathrm{C}$ to separate $\mathrm{RBCs}$ and serum. The serum samples were evaluated for different toxicity markers like Aspartate aminotransferase (AST), Alanine transaminase (ALT), Blood Urea Nitrogen (BUN) and Creatinine levels. by utilizing commercial kits (Accurex ${ }^{\circledR}$ ) available in the market. Harvested RBCs were also studied for their morphological changes as per the same protocol described under SEM analysis of hemolysis study. Organ toxicity was evaluated by analysis of tissue samples of harvested spleen, liver and kidney which were collected and fixed in 10\% Neutral Buffered 
Formalin followed by their embedding in paraffin for tissue sectioning. Tissues were stained with Hematoxylin and Eosin (H\&E) for microscopic examination and observed for presence of toxicity depicting sites.

\section{Results}

\subsection{Lyophilization}

Sucrose, dextrose, inulin, trehalose and mannitol were screened at 5\% w/v concentration level. The ratio of size $(\mathrm{Sf} / \mathrm{Si})$ i.e. size after reconstitution of freeze-dried product and size before freeze drying was 1.06 in the case of 5\% mannitol with good reconstitution behavior. Once mannitol was finalized as lyoprotectant, different concentration of Mannitol was optimized.It was observed that $5 \%$ mannitol retained original quality attributes of formulation

Table S1: Freeze drying of PTX-Biosurfactant nanoparticles with different lyoprotectants

\begin{tabular}{|c|c|c|c|c|c|c|c|c|}
\hline \multirow{2}{*}{$\begin{array}{c}\begin{array}{c}\text { Lyoprotect } \\
\text { ant }\end{array} \\
(5 \%)\end{array}$} & \multicolumn{3}{|c|}{ Before freeze drying } & \multicolumn{3}{|c|}{ After freeze drying } & \multirow{2}{*}{$\begin{array}{l}\text { Ratio } \\
\text { (Sf/Si) }\end{array}$} & \multirow{2}{*}{$\begin{array}{c}\text { R. } \\
\text { score }\end{array}$} \\
\hline & $\begin{array}{c}\text { Particle } \\
\text { size (nm) }\end{array}$ & PDI & $\begin{array}{l}\text { \% drug } \\
\text { loading }\end{array}$ & $\begin{array}{c}\text { Particle size } \\
\text { (nm }\end{array}$ & PDI & $\begin{array}{l}\text { \% drug } \\
\text { loading }\end{array}$ & & \\
\hline Sucrose & & & & $467.5 \pm 59.7$ & $\begin{array}{c}0.421 \pm \\
0.096\end{array}$ & $\begin{array}{c}18.94 \pm \\
1.23\end{array}$ & 1.93 & $*$ \\
\hline Inulin & & & & $289.4 \pm 17.9$ & $\begin{array}{c}0.234 \pm \\
0.043\end{array}$ & $\begin{array}{c}18.72 \pm \\
1.89\end{array}$ & 1.19 & $* * *$ \\
\hline Mannitol & $\begin{array}{c}241.5 \pm \\
12.3\end{array}$ & $\begin{array}{c}0.213 \pm \\
0.058\end{array}$ & $\begin{array}{c}19.72 \pm \\
2.01\end{array}$ & $256.7 \pm 18.6$ & $\begin{array}{c}0.228 \pm \\
0.037\end{array}$ & $\begin{array}{c}20.02 \pm \\
1.17\end{array}$ & 1.06 & $* * *$ \\
\hline Dextrose & & & & $471.2 \pm 53.4$ & $\begin{array}{c}0.402 \pm \\
0.106\end{array}$ & $\begin{array}{c}19.57 \pm \\
1.42\end{array}$ & 1.95 & $* *$ \\
\hline Trehalose & & & & $483.1 \pm 47.3$ & $\begin{array}{c}0.521 \pm \\
0.076\end{array}$ & $\begin{array}{c}18.99 \pm \\
1.76\end{array}$ & 2.00 & $*$ \\
\hline
\end{tabular}

Values are expressed as mean $\pm \mathrm{SD}(\mathrm{n}=3)$

$\mathrm{Sf} / \mathrm{Si}$ ratio of particle size after freeze drying to particle size before freeze drying.

*** Reconstitution in $0.5 \mathrm{ml}$ water and cake was easily redispersed within 20 s by mere shaking.

** Reconstitution in $0.5 \mathrm{ml}$ water and cake was redispersed within 60 s by vortexing.

* Reconstitution in $0.5 \mathrm{ml}$ water and cake was redispersed in more than 120 s by vortexing. 
Table S2: Freeze drying of PTX-Biosurfactants nanoparticles with different concentration of mannitol

\begin{tabular}{|c|c|c|c|c|c|c|c|c|}
\hline \multirow[t]{2}{*}{ Mannitol } & \multicolumn{3}{|c|}{ Before freeze drying } & \multicolumn{3}{|c|}{ After freeze drying } & \multirow{2}{*}{$\begin{array}{l}\text { Ratio } \\
(\mathbf{S f} / \mathrm{Si})\end{array}$} & \multirow{2}{*}{$\begin{array}{c}\text { R. } \\
\text { score }\end{array}$} \\
\hline & $\begin{array}{c}\text { Particle } \\
\text { size }(\mathrm{nm})\end{array}$ & PDI & $\begin{array}{l}\text { \% drug } \\
\text { loading }\end{array}$ & $\begin{array}{l}\text { Particle size } \\
\quad(\mathrm{nm}\end{array}$ & PDI & $\begin{array}{l}\text { \% drug } \\
\text { loading }\end{array}$ & & \\
\hline $2.5 \%$ & & & & $293.6 \pm 32.2$ & $\begin{array}{c}0.329 \pm \\
0.084\end{array}$ & $\begin{array}{c}19.06 \pm \\
2.31\end{array}$ & 1.17 & $* * *$ \\
\hline $5 \%$ & $\begin{array}{c}249.7 \pm \\
28.4\end{array}$ & $\begin{array}{c}0.230 \pm \\
0.048\end{array}$ & $\begin{array}{c}19.21 \pm \\
1.06\end{array}$ & $261.3 \pm 21.4$ & $\begin{array}{c}0.219 \pm \\
0.051\end{array}$ & $\begin{array}{c}19.67 \pm \\
1.54\end{array}$ & 1.04 & $* * *$ \\
\hline $7.5 \%$ & & & & $294.6 \pm 19.4$ & $\begin{array}{c}0.301 \pm \\
0.056\end{array}$ & $\begin{array}{c}18.97 \pm \\
1.68\end{array}$ & 1.17 & $* * *$ \\
\hline $10 \%$ & & & & $282.5 \pm 18.6$ & $\begin{array}{c}0.234 \pm \\
0.064\end{array}$ & $\begin{array}{c}20.32 \pm \\
0.83\end{array}$ & 1.13 & $* * *$ \\
\hline
\end{tabular}

Values are expressed as mean $\pm \mathrm{SD}(\mathrm{n}=3)$

$\mathrm{Sf} / \mathrm{Si}$ ratio of particle size after freeze drying to particle size before freeze drying.

Table S3: Release kinetics of PTX core-shell type nanocapsules

Release $\quad \mathrm{R}^{2} \quad \mathrm{n}$

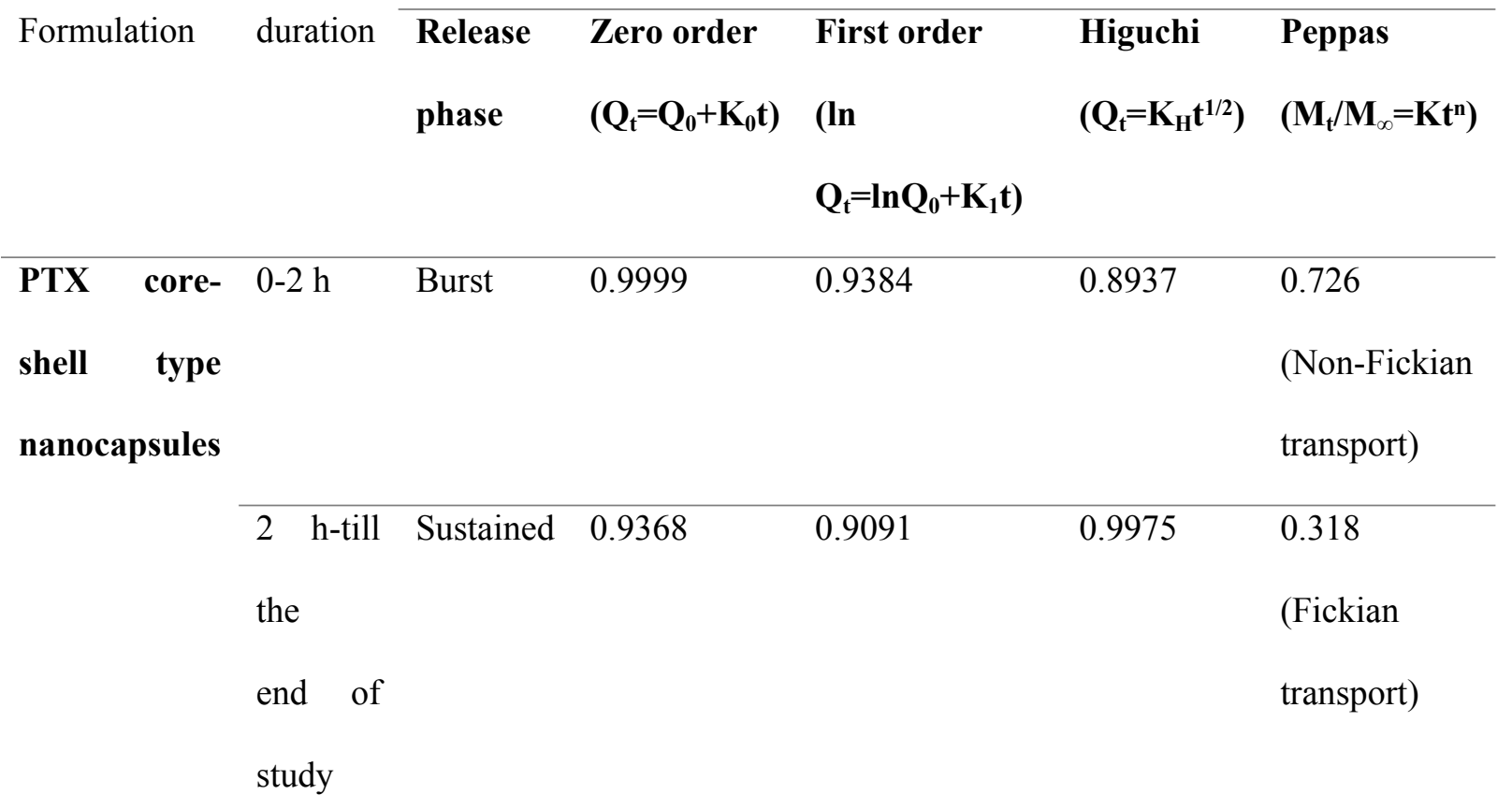


Where, $Q_{t}$ is the amount of drug released in time $t, Q_{0}$ is the initial amount of drug and $K_{0}, K_{1}, K_{H}$ and $\mathrm{K}$ are release rate constants for zero order, first order, Higuchi and Peppas equation. $\mathrm{M}_{\mathrm{t}}$ and $\mathrm{M}_{\infty}$ are release value at time $\mathrm{t}$ and end point respectively for Peppas release model. Since the release was in biphasic pattern, it was divided into two parts, where $0-2 \mathrm{~h}$ was considered as burst release phase and $2 \mathrm{~h}$ onwards the sustain release pattern was evaluated. 